\title{
Analysis of citrus peels-based polygeneration plant for hydrogen, heat, power and DME production: energy and exergy analysis
}

\author{
Mauro Prestipino ${ }^{1, *}$, Vitaliano Chiodo ${ }^{2}$, Giuseppe Bonura ${ }^{2}$, Susanna Maisano ${ }^{2}$, Sebastian \\ Brusca $^{1}$, and Antonio Galvagno ${ }^{1}$ \\ ${ }^{1}$ Department of Engineering, University of Messina, C.da Di Dio, Messina, 98166, Italy. \\ ${ }^{2}$ Institute CNR-ITAE, via Salita S. Lucia sopra Contesse 5, Messina, 98126, Italy.
}

\begin{abstract}
The energy sustainability of producing biofuel from wet bioresidues needs proper energy integration to ensure sustainable exploitation. This study analyses the potentials of combined hydrogen, heat, power, and LOHC (Liquid Organic Hydrogen Carrier) production from the residues of citrus juice production, at a factory scale. In this work, the main constituents of LOHC are DME (Dimethyl ether) and methanol. The proposed system is based on air-steam gasification and direct $\mathrm{CO}_{2}$-to-DME process, integrated with hydrogen purification and a CHP unit. The DME reactor is operated at 30 bar in the temperature range 493-533 K. A thermodynamic model, which is validated experimentally, simulates the proposed polygeneration system. In addition to the potential amount of biofuel, hydrogen production, and net power production, the energy and exergy efficiencies are analyzed. Despite the variation of $\mathrm{LOHC}$ yield with the temperature, the results show that the whole system's energy efficiency is not affected, while the small difference among the exergy efficiencies is negligible.
\end{abstract}

\section{Introduction}

Global warming and depletion of fossil fuel energy resources are two of the most significant challenges of these years. Thus, a rapid transition towards renewables energy systems is crucial to avoid climate change and its dangerous consequences for humanity. Renewable energy systems need proper location and integration due to the variability of the primary energy source [1], and its distribution in the territory [2] in the case of bioenergy. Among the primary renewable energy sources, biomass covers a crucial role, with a share of $60 \%$ of the total global renewable energy use $[3,4]$. Different materials, such as waste, agriculture residue [5,6], and forest residues have been studied and applied as feedstock for gasification and syngas production in a temperature range 973-1773 K [7-9].

The first and most common application of gasification was to produce a fuel gas for heating and power in internal combustion engine. As biomass gasification technologies were improved [3], biomass-derived syngas has been often combined in biorefinery platforms also to produce liquid bio-fuels and/or chemicals via Fischer-Tropsch (FT) technology [10,11].

\footnotetext{
* Corresponding author: mprestipino@unime.it
} 
In this context, the chemical transformation of $\mathrm{CO}_{2}$ into useful products and fuels, such as methanol $(\mathrm{MeOH})$, dimethyl ether (DME), urea, hydrocarbons, etc., is an attractive way of recycling $\mathrm{CO}_{2}$ and thereby controlling its emission into the atmosphere [12,13]. In particular, DME is considered a prospective "future fuel", usable either as a fuel itself, or starting material for the production of a range of chemicals, such as oxygenates, olefins and hydrocarbon fuels (gasoline, jet fuel), or as an efficient $\mathrm{H}_{2}$ carrier for fuel cells and other applications $[8,12,14]$.

Usually, poly-generation systems for chemical production and power generation have mainly been studied for methanol production or even for Fischer-Tropsch products. More studies are needed for the analysis of small scale systems fed by residual biomass and integrated with the production process of the feedstock. Among these, the integration of once-through DME and IGCC (Integrated gasification combined cycle) plants is demonstrated to be an attractive alternative for the production of clean energy for power generation. DME production costs were comparable with those for fuels such as natural gas, liquefied petroleum gases and others [10][14]. The simulation of a poly-generation electricity-DME system based on coal gasification shows higher net efficiency than the traditional IGCC plants (over 4\%) [14]. Similarly, a higher energy saving ratio has been attained in a natural gas-based integrated system for electricity and DME production. Energy savings of $10.2 \%$ were obtained in the poly-generation system compared with a stand-alone system [14]. Simulations of polygeneration systems based on gasification of switchgrass indicated that the overall efficiency for fuel production varied from 57\% for Fischer-Tropsch, 55-61\% for DME and 58-64\% for hydrogen [15]. Moreover, the performance of integrated production of bio-DME and electricity based on once-through DME production and $\mathrm{CO}_{2}$-enhanced gasification of rice straw (biomass) was more efficient than for the corresponding stand-alone system [14].

The DME can be produced by either two-step or single-step processes. The first pathway comprises two reactors with different catalysts for methanol and DME syntheses, while the single-step process of DME production carried out via methanol synthesis and methanol dehydration in a single reactor using a bi-functional catalyst $[10,14]$. Typically, methanol synthesis reaction is carried out on $\mathrm{Cu}-\mathrm{ZnO}-\mathrm{Al}_{2} \mathrm{O}_{3}$ catalysts, although $\mathrm{Cu}-\mathrm{ZnO}-\mathrm{ZrO}_{2}$ catalysts are recently claimed as more active catalytic systems due to a better water tolerance of zirconia with respect to alumina [10,12-14]. In contrast, methanol dehydration reaction takes place fast over a solid acid component.

Recently, the authors analyzed the energy sustainability of citrus residues conversion and valorization through fluidized bed gasification plant integrated into a real citrus juice factory [16]. Results showed that the integration of a gasification-CHP system into the juice industrial cycle could supply 7,875 MWh/year of net electricity. Therefore, the aim of this study is to assess a different pathway of exploiting syngas obtained from citrus peel gasification, with the integration into the citrus juice company. Specifically, the study analyses a polygeneration system for the production of Liquid Organic Hydrogen Carriers (LOHC) consisting of DME and methanol in a single-step reactor, along with the production compressed hydrogen, heat, and power. The heat recovery units provide heat to the citrus juice factory for drying the residual biomass as well as for citrus processing. A thermodynamic simulation model is used for the analysis of the polygeneration system, where both the gasification and the LOHC reactors are modeled by minimizing the Gibbs free energy of the components. The assessment of energy yields of the different products, as well as the energy and exergy efficiencies, is carried out for a polygeneration plant at the scale of a large citrus juice factory in Italy.

\section{Materials and Methods}




\subsection{Polygeneration Process}

Figure 1 depicts the block flow diagram of the polygeneration process producing electricity, hydrogen, and the Liquid Organic Hydrogen Carrier (LOHC). The process is simulated in PRO/II Process Engineering simulation software environment and then validated through experimental and literature data.

The polygeneration process is integrated with the citrus juice factory that provides the feedstock, which is citrus peel with $15 \%$ water content. The reference juice factory that has been considered in this work is a large Sicilian citrus juice factory with the potential to process $72,000 \mathrm{t} / \mathrm{year}$ of fresh citrus fruit, leading to $6,869 \mathrm{t} / \mathrm{year}$ of citrus residues on a dry basis. A fluidized bed gasifier is used as the reference technology for the conversion of citrus peel to syngas. The conversion performance of citrus peel in the fluidized are based on the results obtained from the research work Galvagno et al [16], where a thermodynamic simulation model was realized and validated to assist in the design of a gasification process that integrates a CHP unit and the juice production process. Specifically, in this work, the gasifier is operated at $1123 \mathrm{~K}$, atmospheric pressure, and $\mathrm{S} / \mathrm{B}=0.12$. At these conditions, the cold gas efficiency resulted 0.75 , while the syngas LHV was $5.69 \mathrm{MJ} / \mathrm{Nm}^{3}$.

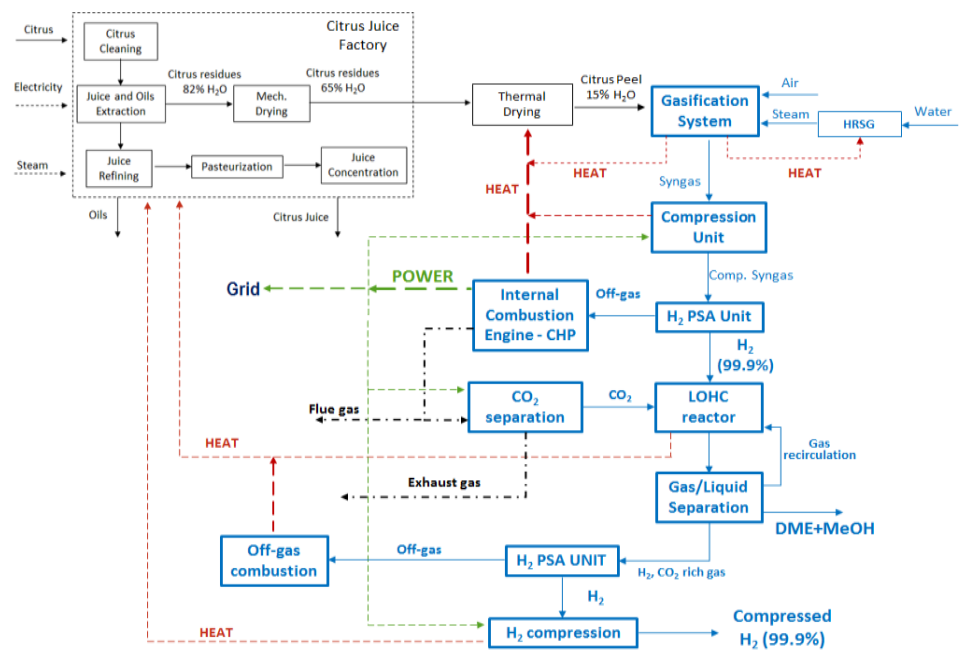

Fig. 1. Block flow diagram of the integrated polygeneration system. The blocks in blue are the units added in the proposed scenario. Blue lines and solid black lines are material streams, red dashed lines are heat streams, green dashed lines are electrical power streams, and black dashed lines are flue-gas and exhaust gas.

After the gasification unit, the process model presented in Figure 1 shows a pressure swing adsorption (PSA) unit for hydrogen separation. The main energy input of this unit is the syngas compression, reaching 7 bar and subsequent hydrogen separation efficiency of 0.7 [17]. The hydrogen separation unit is implemented in the proposed system to obtain the desired $\mathrm{H}_{2} / \mathrm{CO}_{2}(\mathrm{~mol} / \mathrm{mol})$ ratio in the stream entering the LOHC reactor. In this work, the isentropic efficiency for the syngas and hydrogen compression is 0.72 [18].

After the hydrogen separation, the off-gas of the PSA unit is delivered to a combined heat and power (CHP) unit based on an internal combustion engine designed for syngas combustion. The constructor provided the performance of the CHP unit, which is 0.37 for the electrical efficiency and 0.44 for the thermal one. The cogenerated heat is produced in the form of hot water at $363 \mathrm{~K}$, which is used in the juice factory for the thermal drying of citrus peel, reducing the water content from $65 \%$ to $15 \%$. The heat used in the drying unit is 1.54 
$\mathrm{kWh}$ per $\mathrm{kg}$ of biomass on a dry basis. A fraction of the flue gas from the CHP unit is diverted to the $\mathrm{CO}_{2}$ separation unit, where a VPSA system separates the carbon dioxide from the other gases (mainly nitrogen and oxygen). The energy required for $\mathrm{CO}_{2}$ separation is derived from the work of Jiang et al [19], where they show that the electricity consumption is about 0.79 $\mathrm{MJ} / \mathrm{kg}_{\mathrm{CO} 2}$, leading to $96 \%$ of purity and $91 \%$ recovery of $\mathrm{CO}_{2}$. The amount of flue gas directed to the carbon capture section is determined from the amount of pure hydrogen separated and by keeping the molar ratio $\mathrm{H}_{2} / \mathrm{CO}_{2}=3$.

A thermodynamic reactor models the $\mathrm{LOHC}$ reactor by minimizing the Gibbs free energy of the components. The model is validated experimentally in a once-through lab-scale setup that allows carrying the DME synthesis in a one-step process at 30 bar. More details on the LOHC process are described in section 2.2. Then the model is run in a configuration where some of the unconverted gas in recycled to increase the total mass flow that enters the LOHC reactor and the $\mathrm{LOHC}$ flow rate per unit of feedstock introduced in the polygeneration system. The recycled stream consists of only the permanent gases obtained after the condensation of the LOHC at a pressure of about 30 bar and $80^{\circ} \mathrm{C}$. Then, the residual gas mixture is sent to a PSA unit for hydrogen separation (the main component) from carbon dioxide and a marginal fraction of carbon monoxide. After its purification, hydrogen is compressed to 300 bar for storage in a three-stage compression. In this unit, heat recovery from the intercooler stages is included. The off-gas of this last PSA unit is a mix of residual hydrogen, carbon monoxide and carbon dioxide, and it is exploited for saturated steam generation at $453 \mathrm{~K}$, which in the production process of citrus juice. The thermal efficiency of this steam generator is assumed by $90 \%$.

The global energy efficiency of the polygeneration process presented in study is assessed according to the following equation:

$$
\eta_{\text {poly }}=\frac{E_{D M E}+E_{M e O H}+E_{\text {heat_net }}+E_{\text {elect_net }}}{E_{\text {biom }}}
$$

Where $E_{D M E}$ and $E_{M e O H}$ are the chemical energy carried by the LOHC, $\mathrm{E}_{\text {heat_net }}$ is the net thermal energy that consist of the total heat recovery of the system subtracted of the fraction used for the gasification agents (air and steam) and for drying the feedstock to 15 of water content. $E_{\text {elect_net }}$ is the electricity generated in the CHP unit subtracted of the auxiliaries for the gasification process (assumed $15 \%$ of the potential electricity generation if the whole syngas is used in the CHP unit), the electricity needed for syngas compression, $\mathrm{CO}_{2}$ separation, and hydrogen compression for its storage at 300 bar. The latter three contributions are evaluated supported by the process simulation. Similarly, the same calculation expressed in Eq. 1 is used for estimating the exergy efficiency of the integrated polygeneration process. The exergy factor, which converts the energy into the corresponding exergy values, is 1 in the case of electricity. A common practice for evaluating the chemical exergy of the technical fuels is using statistical correlations between chemical exergy and the lower heating values of fuels when the ultimate and proximate analysis are known [20]. The ratio between chemical exergy $\left(e_{i, o r g}^{c h}\right)$ and LHV is expressed as $\beta$ :

$$
\beta=\frac{e_{i, o r g}^{c h}}{L H V_{i, o r g}}
$$

One of the most used correlation for liquid fuels (when $\mathrm{O} / \mathrm{C} \leq 1$ ) is the following one.

$$
\beta=1.0374+0.0159 \frac{H}{C}+0.0567 \frac{O}{C}
$$

Where $\frac{H}{C}$ and $\frac{O}{C}$ are the atomic ratios of the elements. For dry biomass, the following simple method has been adopted in this work. 


$$
e_{d b}^{c h}=1.047 H H V_{d b}
$$

This simplified expression used for biomass on a dry basis showed an agreement with the more rigorous methods by Szargut and Styrylska within $+/-2 \%$ [20]. The physical exergy of a heat transfer is calculated as follows:

$$
E_{\text {heat_ex }}=\left(1-\frac{T_{0}}{T}\right) H_{\text {heat }}
$$

Where $E_{\text {heat }}$ and $E_{\text {heat_ex }}$ are the thermal energy and the corresponding exergy involved in the heat transfer.

\section{$2.2 \mathrm{LOHC}$ reactor}

An innovative approach to the production of DME is the direct $\mathrm{CO}_{2}$ hydrogenation process, which is given by Eq. (6):

$$
2 \mathrm{CO}_{2}+6 \mathrm{H}_{2} \leftrightarrows \mathrm{CH}_{3} \mathrm{OCH}_{3}+3 \mathrm{H}_{2} \mathrm{O}\left(\Delta H^{\circ}=-122.2 \mathrm{~kJ} \mathrm{~mol}^{-1}\right)
$$

A decrease in reaction temperature or an increase in reaction pressure should favor the synthesis of DME from a thermodynamic point of view. However, from a kinetic point of view, only an increase of reaction temperature above $513 \mathrm{~K}$ facilitates the $\mathrm{CO}_{2}$ activation rate due also to the competitive formation of methanol (Eq. (7)) or carbon monoxide (CO) (Eq. (8)) $[10,11]$.

$$
\begin{gathered}
\mathrm{CO}_{2}+3 \mathrm{H}_{2} \leftrightarrows \mathrm{CH}_{3} \mathrm{OH}+\mathrm{H}_{2} \mathrm{O}\left(\Delta H^{\circ}=-49.4 \mathrm{~kJ} \mathrm{~mol}^{-1}\right) \\
\mathrm{CO}_{2}+\mathrm{H}_{2} \leftrightarrows \mathrm{CO}+\mathrm{H}_{2} \mathrm{O}\left(\Delta H^{\circ}=+41.2 \mathrm{~kJ} \mathrm{~mol}^{-1}\right)
\end{gathered}
$$

For these reasons, a catalyst with specific active sites is required to avoid the formation of undesired by-products $[10,12]$. In fact, after methanol is generated over a metal-oxide catalyst functionality, it is immediately dehydrated over a neighboring acidic site, thereby enhancing the forward reaction and limiting the $\mathrm{CO}_{2}$ consumption via reverse water gas shift reaction (RWGS) reaction [3].

The direct catalytic hydrogenation of $\mathrm{CO}_{2}$ into DME is typically performed in presence of physical/mechanical mixtures between a $\mathrm{Cu}$-based methanol synthesis catalyst (usually, $\mathrm{CuO}-\mathrm{ZnO}-\mathrm{Al}_{2} \mathrm{O}_{3}$ or $\mathrm{CuO}-\mathrm{ZnO}-\mathrm{ZrO}_{2}$ ) and a solid acid catalyst, such as $\gamma-\mathrm{Al}_{2} \mathrm{O}_{3}$, silicaalumina (less or more modified) or different types of zeolites, responsible for methanol dehydration [12][13].

In the light of the foregoing consideration, performances of a hybrid catalyst system for the one-step of DME synthesis has been evaluated at different temperatures mainly in terms of $\mathrm{CO}_{2}$ conversion (\%) $\left[\mathrm{mol} \mathrm{CO}_{2}\right.$ in $-\mathrm{mol} \mathrm{CO}_{2}$ out $\mathrm{mol} \mathrm{CO}_{2}$ out $]$ and selectivity (\%) to DME, $\mathrm{CO}$ and Methanol [mol $\mathrm{C}_{x}$ product $/ \mathrm{mol} \mathrm{CO}_{2}$ conv.].

A hybrid catalyst was prepared by combinating $\mathrm{CuZnZr}$ methanol catalyst with an homemade zeolite structure: ferrierite (FER) and mordenite (MOR). Successively, the catalytic activity of the hybrid system has been investigated in a fixed-bed stainless steel reactor (i.d., $4 \mathrm{~mm} ; l ., 200 \mathrm{~mm}$ ) at temperatures ranging from 493 to $533 \mathrm{~K}$ and a total pressure of 30 bar $\left(F=2.4 S T P \mathrm{~L} / \mathrm{h} ; \mathrm{CO}_{2} / \mathrm{H}_{2} / \mathrm{N}_{2}=3 / 9 / 1\right) .0 .250 \mathrm{~g}$ of multifunctional catalyst (40-70 mesh), and diluted with granular $\mathrm{SiC}(0.25 \mathrm{~g})$, have been used. Prior to each test, the catalyst was reduced in situ at $573 \mathrm{~K}$ for $1 \mathrm{~h}$ in pure hydrogen flow at atmospheric pressure. The reaction stream was analyzed by gas chromatography equipped with a two-column separation system connected to a flame ionized detector (FID) and thermal conductivity detector (TCD), respectively. Conversion-selectivity data were calculated by both internal standard and mass- 
balance methods, each data set being obtained, with an accuracy of $\pm 3 \%$, from an average of three independent measurements

\section{Results and Discussion}

The $\mathrm{CO}_{2}$ hydrogenation activity data, at reaction temperature ranging from $493 \mathrm{~K}$ to $533 \mathrm{~K}$, pressure 30 bar, are reported in Table 1 , in terms of $\mathrm{CO}_{2}$ conversion and selectivity to DME, $\mathrm{CO}$, and $\mathrm{MeOH}$. First, it is relevant to underline that no other hydrocarbons have been found under the adopted experimental conditions. From Table 1 is possible to observe that the $\mathrm{CO}_{2}$ conversion progressively increases with temperature, achieving a maximum value of $21.2 \%$ at $533 \mathrm{~K}$, while, a decreasing of DME selectivity $\left(S_{\mathrm{DME}}\right)$ from $51.9 \%$ to $36.5 \%$ between 493 $\mathrm{K}$ and $533 \mathrm{~K}$. These results shows that the system works under a prevailing kinetic regime with $\mathrm{CO}_{2}$ conversion values always lower than that expected from thermodynamic equilibrium data $(>26 \%$ at $533 \mathrm{~K})$, at all reaction temperature considered, which is in accordance with other authors [10][14][12][13][21][22][23][24][15].

Table 1. Catalytic results of $\mathrm{CO}_{2}$ dehydrogenation reaction $\left(\mathrm{H}_{2} / \mathrm{CO}_{2}: 3 \mathrm{~mol} / \mathrm{mol} ; \mathrm{P}=30\right.$ bar $)$

\begin{tabular}{|c|c|c|c|c|}
\hline \multirow{2}{*}{ Temperature (K) } & \multirow{2}{*}{$\begin{array}{c}\text { CO } \\
\text { (\%) }\end{array}$} & \multicolumn{3}{|c|}{ conv. } \\
\cline { 3 - 5 } & & $D M E$ & $M e O H$ & $\mathrm{CO}$ \\
\hline 493 & 10.4 & 51.9 & 16.3 & 31.8 \\
\hline 513 & 16.9 & 40.7 & 14.5 & 44.8 \\
\hline 533 & 21.2 & 36.5 & 14.4 & 49.1 \\
\hline
\end{tabular}

Similarly, a slight but regular decrease of $S_{\mathrm{MeOH}}$ is recorded throughout the temperature range investigated, attaining a threshold value (ca. $14 \%$ ) at $533 \mathrm{~K}$, as a result of the increased competition between the methanol synthesis rate and its dehydration to DME. The selectivity of CO follows an opposite trend in respect of $S_{\mathrm{DME}}$, by increasing from $31.8 \%$ to $49.1 \%$ in the range 493-533 K, showing values higher than the equilibrium ones $(<20 \%)$ [13][25]; this confirms that, under the reaction conditions, the hydrogenation of $\mathrm{CO}_{2}$ runs in a predominantly kinetic condition. Summarizing, the production of DME in a single-step from $\mathrm{CO}_{2}-\mathrm{H}_{2}$ mixture using a traditional catalytic hybrid system it has been possible, hence a reasonable operating comprise for operative rates (30 bar and 493-533 K) has been revealed.

As mentioned in section 2, the biomass gasification process is modeled in an ideal Gibbs reactor and validated experimentally in a previous study [13]. In this work, the conversion of carbon dioxide and hydrogen into DME and $\mathrm{MeOH}$ is modeled in a Gibbs reactor as well, and its experimental validation is shown in Figure 2, where the molar fractions of the exiting permanent gas (a) and the condensable product (b) are presented for both simulated and experimental reactors. It is possible to observe a good agreement between experimental and simulated results in the investigated temperature range and in terms of both the variation trend and values. In accordance with the experimental results, in the simulation model, specific values of $\mathrm{CO}_{2}$ conversion and a global temperature approach are adopted to account for the deviation from the thermodynamic conditions and the effects of temperature on the kinetic-controlled reaction. 


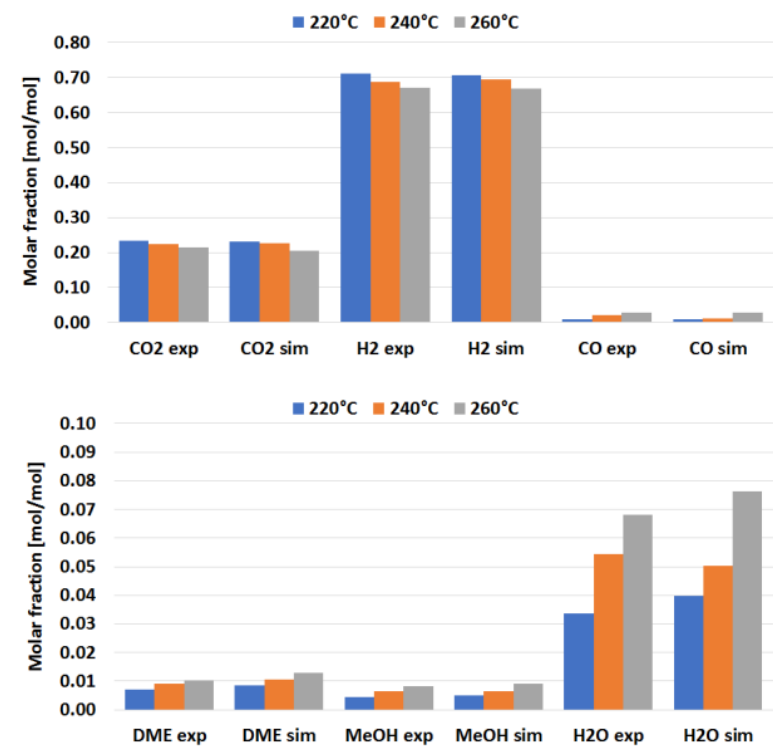

Fig. 2. Experimental and simulated gas composition of the products of the LOHC reactor

Specifically, a variable temperature approach in the range $15-45^{\circ} \mathrm{C}$, and variable $\mathrm{CO}_{2}$ conversion in the range $10-20 \%$ are used. Figure 2 shows the correlation between these two parameters and the temperature. The global temperature approach decreases with the temperature in order to follow the increasing trend of DME formation. Indeed, the formation of DME is not thermodynamically favored as the temperature increases, unless the process is kinetically controlled, as it is at the investigated conditions. This involves the decrease of the temperature approach to keep the DME formation increasing with the temperature. It is also possible to observe a good linear correlation for both conversion and global temperature approach.

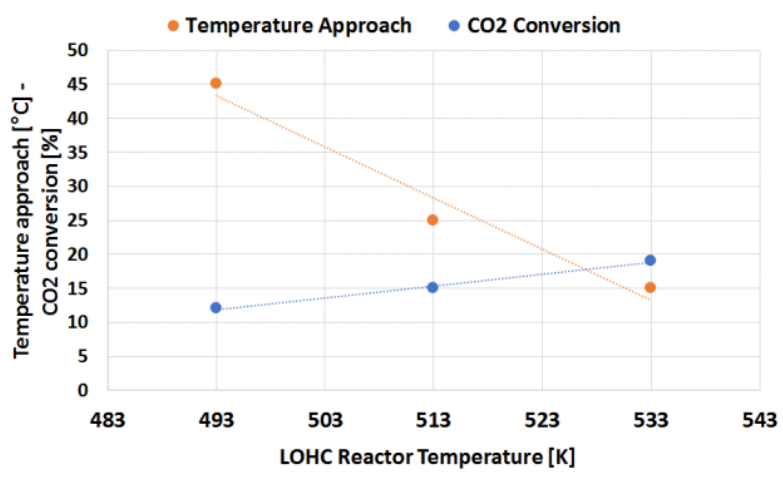

Fig. 3. Dependence of temperature approach (orange) and conversion (blue) on reactor temperature

After the model validation, the whole process is simulated in a configuration that includes the recirculation of products exiting the LOHC reactor. Figure 4 shows the energy and exergy outputs of the process and expressed per unit mass of feedstock entering the reactor on a dry basis $\left(\mathrm{kWh} / \mathrm{kg}_{\mathrm{db}}\right)$, obtained at $260^{\circ} \mathrm{C}$. These values represent the available energy, net of the internal consumptions of the process (i.e. compression, drying, and auxiliaries). Specifically, the energy stream named Heat -Syngas + CHP refers to the net heat obtained from the CHP 
unit, cooling syngas from $973 \mathrm{~K}$ to $473 \mathrm{~K}$, and the heat recovery in the syngas compression unit, subtracted of the heat need in the drying unit. As expected, the electricity generation is the primary energy output of the process since its share is $41 \%$ of the total energy output. Hydrogen and LOHC are ranked second and third as their shares are $22 \%$ and $19 \%$, respectively. Excluding the heat from the CHP unit, which is used in the drying unit, the highest contribution to net heat production comes from the combustion of the off-gas produced in the second PSA unit, which leads to the production of compressed hydrogen. From the simulation, it is obtained that this off-gas stream consists of $\mathrm{CO}_{2}(48 \% \mathrm{~mol} / \mathrm{mol}), \mathrm{CO}$ $(7 \% \mathrm{~mol} / \mathrm{mol})$ and $\mathrm{H}_{2}(45 \% \mathrm{~mol} / \mathrm{mol})$. Due to the high thermal demand of the factory that is integrated with the proposed process, this off-gas stream is used for the production of heat in the form of saturated steam at $393 \mathrm{~K}$. It follows that the corresponding exergy value is much lower than its energy content. However, this stream could be used for additional electricity production by fuel cells, gas turbine, or reciprocating engines. In this additional hypothetical scenario, the resulting electrical energy/exergy would be affected by a lower conversion efficiency than in the case of steam production, even if the exergy factor would be higher than in the case of steam production.

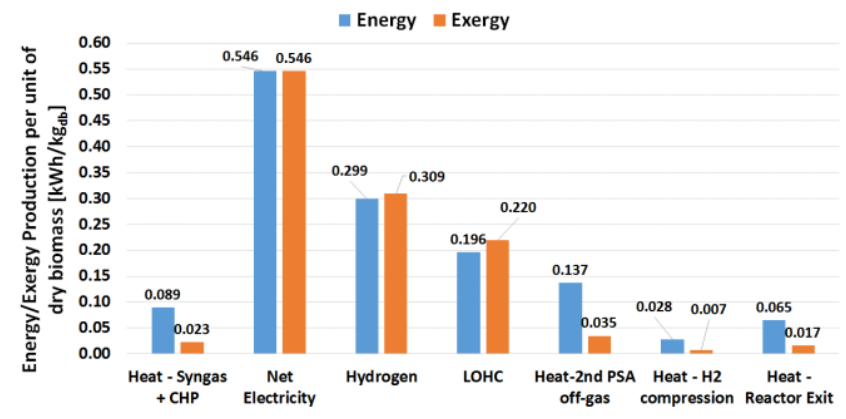

Fig. 4. Energy and exergy yields of the polygeneration system (per unit of biomass on a dry basis)

The evaluation of the global energy and exergy efficiencies variation of the proposed polygeneration system when the temperature of the LOHC reactor varies is presented in Figure 5. The energy efficiency is constant when the LOHC reactor varies because the higher production of LOHC is compensated with the reduction of compressed hydrogen, the heat generated from LOHC off-gas combustion (non-recycled fraction of permanent gas), and the heat recovery from the compression stages (due to the lower hydrogen flow rate to be compressed).

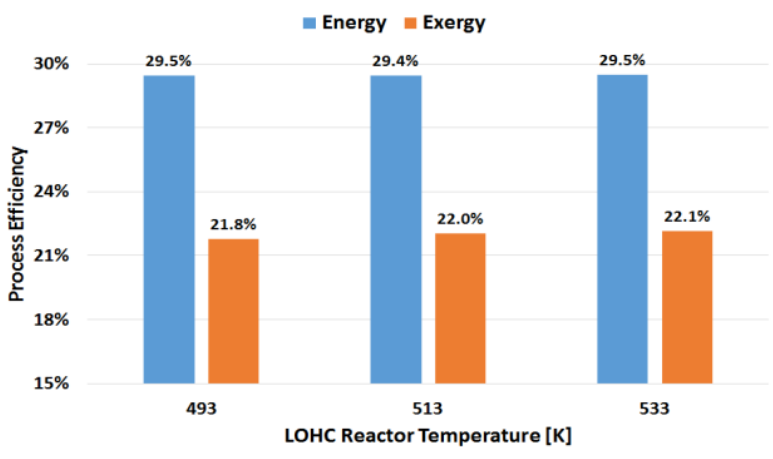

Fig. 5 Global energy and exergy efficiencies of the polygeneration process

The exergy efficiencies are always lower than the corresponding energy efficiencies. The reasons for this expected behavior are tow folds. The biomass input is a high quality of energy 
form and its exergy values are higher than the energy one, which involves high exergy input to the system. Furthermore, heat in the form of low-temperature steam is a low-quality form of energy, leading to the reduction of the exergy share due to heat production. Contrarily to the energy efficiency, the slight increase of the exergy efficiency with the temperature (from 21.7 to $22.1 \%$ ) is due to the reduction of heat recovery (low-quality energy), while the production of LOHC (high-quality energy) increase. It follows that the higher hydrogen production rate at lower temperature, despite its high-quality energy, cannot compensate the reduction of other energy output. However, it should be pointed out that the variations of the exergy at the investigated temperature range are still shallow, and the effect on the global energy and exergy efficiencies could be neglected. This result involves that other analyses, such as techno-economic, sustainability, and environmental assessments, are needed to define the best operating conditions. From the viewpoint of the LOHC production rate, 533 $\mathrm{K}$ is the condition that maximizes its yield per unit of biomass rate at the investigated conditions. As mentioned in section 2, the proposed system is designed to be integrated into a citrus juice factory with the capacity to produce $6,869 \mathrm{t} / \mathrm{year}$ of citrus peel on a dry basis. From the results in Figure 4, it follows that 4,561 MWh/year of electricity, and a total 2,192 $\mathrm{MWh} /$ year of heat, which is delivered to the citrus factory. The installed CHP unit is 0.760 MW, assuming the plant is working $6000 \mathrm{~h} /$ year. Regarding the fuel products, the proposed system has the capacity of producing $186 \mathrm{t}$ /year of LOHC (the highest yield) when the reactor is operated $533 \mathrm{~K}$. At these conditions, the annual hydrogen production is $62 \mathrm{t} / \mathrm{year}$.

\section{Conclusions}

This work investigates an alternative pathway than CHP for the integration of residual biomass gasification with the factory where the organic residue or byproduct is generated. The proposed system consists of a gasification unit, two hydrogen separation units (PSA technology), one carbon dioxide separation unit (VPSA technology), and a reactor of liquid organic hydrogen carrier (LOHC). The performance of the combined production of hydrogen, heat, power, and LOHC is assessed. The analysis of the proposed polygeneration system can be summarized as follows:

- The LOHC yield increases with temperature, while the hydrogen production follows an opposite trend. However, global energy efficiency is not affected by the LOHC reactor temperature, while the variation of the global exergy efficiencies are negligible.

- Electricity ranked as the first energy yield per unit of biomass introduced in the gasification reactor on a dry basis, being $0.546 \mathrm{kWh} / \mathrm{kg}_{\mathrm{db}}$, followed by compressed hydrogen and LOHC.

- Combustion of the off-gas of the second PSA stage for hydrogen purification leads to the production of $0.137 \mathrm{kWh} / \mathrm{kg}_{\mathrm{db}}$ of saturated steam at $120^{\circ} \mathrm{C}$.

- The annual net electricity generation is 4,561 MWh/year, while the hydrogen and LOHC production is $62 \mathrm{t} /$ year and $186 \mathrm{t} /$ year, respectively, when the LOHC reactor is operated at $533 \mathrm{~K}$ and 30 bar.

The authors thank the AVEVA group for providing the AVEVA PRO/II Simulation software used in this work.

\section{References}

1. F. Chiacchio, D. D’Urso, F. Famoso, S. Brusca, J. I. Aizpurua, and V. M. 
Catterson, Energy 151, 605 (2018)

2. S. Brusca, F. Famoso, R. Lanzafame, M. Messina, and P. Monforte, Energy Procedia 126, 353 (2017)

3. K. Atsonios, A. Nesiadis, N. Detsios, K. Koutita, N. Nikolopoulos, and P. Grammelis, Fuel Process. Technol. 197, 106188 (2020)

4. K. Özdenkçi, M. Prestipino, M. Björklund-Sänkiaho, A. Galvagno, and C. De Blasio, Renew. Sustain. Energy Rev. 134, (2020)

5. A. Galvagno, M. Prestipino, V. Chiodo, S. Maisano, S. Brusca, and R. Lanzafame, Energy Procedia 126, 485 (2017)

6. F. Famoso, M. Prestipino, S. Brusca, and A. Galvagno, Appl. Energy 274, 115315 (2020)

7. W. Gadek, M. Mlonka-Mędrala, M. Prestipino, P. Evangelopoulos, S. Kalisz, and W. Yang, E3S Web Conf. 10, 4 (2016)

8. I. L. Motta, N. T. Miranda, R. Maciel Filho, and M. R. Wolf Maciel, Renew. Sustain. Energy Rev. 94, 998 (2018)

9. A. Galvagno, M. Prestipino, V. Chiodo, S. Maisano, and S. Brusca, 020082, (2019)

10. T. Nakyai and D. Saebea, J. Clean. Prod. 241, 118334 (2019)

11. C. De Blasio, in Fundam. Biofuels Eng. Technol., Green Ener (Springer, Cham, 2019), pp. 155-171

12. G. Bonura, F. Frusteri, C. Cannilla, G. Drago Ferrante, A. Aloise, E. Catizzone, M. Migliori, and G. Giordano, Catal. Today 277, 48 (2016)

13. F. Frusteri, M. Cordaro, C. Cannilla, and G. Bonura, Appl. Catal. B Environ. 162, 57 (2015)

14. A. Narvaez, D. Chadwick, and L. Kershenbaum, Energy 188, 116058 (2019)

15. Y. K. Salkuyeh and T. A. Adams, Energy Convers. Manag. 88, 411 (2014)

16. A. Galvagno, M. Prestipino, S. Maisano, F. Urbani, and V. Chiodo, Energy Convers. Manag. 193, 74 (2019)

17. H. R. Sara, B. Enrico, V. Mauro, D. C. Andrea, and N. Vincenzo, Energy Procedia 101, 806 (2016)

18. M. Al-Zareer, I. Dincer, and M. A. Rosen, Appl. Energy 195, 646 (2017)

19. N. Jiang, Y. Shen, B. Liu, D. Zhang, Z. Tang, G. Li, and B. Fu, J. CO2 Util. 35, $153(2020)$

20. K. J. Ptasinski, Efficiency of Biomass Energy (2015)

21. I. Sierra, J. Ereña, A. T. Aguayo, J. M. Arandes, M. Olazar, and J. Bilbao, Appl. Catal. B Environ. 106, 167 (2011)

22. R. Khoshbin and M. Haghighi, Chem. Eng. Res. Des. 91, 1111 (2013)

23. A. García-Trenco, A. Vidal-Moya, and A. Martínez, Catal. Today 179, 43 (2012)

24. S. Allahyari, M. Haghighi, A. Ebadi, and S. Hosseinzadeh, Energy Convers. Manag. 83, 212 (2014)

25. G. Jia, Y. Tan, and Y. Han, Ind. Eng. Chem. Res. 45, 1152 (2006) 